DOI: 10.20472/IAC.2018.037.012

\title{
HAIRONG MU
}

Harper Adams University, United Kingdom

\author{
HUI ZHENG
}

Ocean University of China, China

CHUNYANG WANG

Macau University of Science and Technology, Macau

\section{WHAT AILS FISHERY INSURANCE IN CHINA? - EVALUATING FISHERMEN'S WILLINGNESS TO PAY IN CENTRAL COASTAL AREAS}

\begin{abstract}
:
Despite the remarkable development in its fishery sector, the penetration rate of fishery insurance in China is considerably low. This paper examines the key factors that contribute to the poor performance of fishery insurance in the country and investigates fishermen's willingness to pay (WTP) for the insurance program, based on a survey of 1,280 fishermen in three coastal cities in China. The results indicate fishermen's decision on adoption of an insurance scheme depends on various factors, among which the magnitude of loss, insurance awareness and education level all have positive impact, but annual income and years of fishing experience are more likely to have negative effects. In addition, the mean WTP for fishery insurance is estimated to be CNY 579 per family, which is equivalent to $1.5 \%$ of fishermen's mean annual income. These results provide several policy implications for not only the government but also researchers and insurance companies.
\end{abstract}

\section{Keywords:}

China, fishery insurance, willingness to pay, double-bounded dichotomous choice contingent valuation method, field survey

JEL Classification: Q22, H42 